\title{
Overview of Experimental Investigations for Ares I Launch Vehicle Development
}

\author{
William G. Tomek ${ }^{*}$, Gary E. Erickson. ${ }^{\dagger}$ Jeremy T. Pinier ${ }^{\ddagger}$, and Jeremy L. Hanke ${ }^{\S}$ \\ NASA Langley Research Center, Hampton, Virginia, 23666
}

\begin{abstract}
The Ares I vehicle architecture was the design outcome of the Exploration Systems Architecture Study (ESAS) in response to the Vision For Space Exploration challenge provided by President George Bush in 2004. The Ares I vehicle was designed to carry astronauts into low-Earth orbit to support the International Space Station as well as provide transportation to destinations beyond low-Earth orbit including the Moon and Mars. As part of the Ares I vehicle development, numerous technical disciplines have been conducting analyses on the architecture to evaluate its mission performance and viability.

Since 2005, an extensive aerodynamic experimental wind tunnel testing program has been conducted for a series of Ares I vehicle configurations as the vehicle design matured. These investigations have utilized multiple aerodynamic research facilities across the United States. Wind tunnel testing has been conducted on the Ares I launch vehicle from low speed lift-off conditions to post-separation supersonic conditions. Facilities have included the Langley Research Center (LaRC) Unitary Plan Wind Tunnel (UPWT), the Boeing Polysonic Wind Tunnel (PSWT), the LaRC National Transonic Facility (NTF), the LaRC 14X22 LowSpeed Wind Tunnel, the Arnold Engineering Development Center (AEDC) Von Karman Facilities, and the Marshall Space Flight Center (MSFC) Trisonic Wind Tunnel. Each of the facilities was utilized based on their size, Mach number capability, cost, and productivity.

A number of varied test techniques have been utilized during Ares I aerodynamic characterization experimental investigations. Most of the aerodynamic wind tunnel testing utilized internal strain gauge balances to measure integrated forces and moments. Major concerns to the Performance and Guidance and Control disciplines were the axial force and aerodynamic induced rolling moment components of the vehicle. Specifically protuberance effects on rolling moment and roll control authority are a concern during lift-off and ascent.

Another test technique that has been utilized in the Ares I vehicle development has been the use of surface pressures to measure distributed loads on the vehicle. One percent scale models have been tested in typical 4-foot subsonic/transonic and supersonic facilities. The slenderness of the vehicle has been a challenge in both the integrated force/moment testing as well as in the distributed loads testing. Distributed pressure loads are used by the Structures and Loads disciplines to assist in the design of the external panels and internal structure of the vehicle.

In addition to the ascent aerodynamic experimental testing, some other specialized aerodynamic wind tunnel tests have been conducted. An investigation was conducted to evaluate ground wind loads, launch tower effects, and transition aerodynamics from lift-off to ascent flight. This test provided a database of proximity aerodynamics in the presence of the launch that reduced the risk of vehicle contact to the launch tower. Another specialized stage separation aerodynamic wind tunnel test was conducted in the AEDC Von Karman Facility Tunnel A specifically addressing proximity aerodynamics of the upper stage relative to the first stage. This test provided a more refined stage separation proximity aerodynamic database to eliminate some risk to the program regarding recontact between the two stages during ascent.

This paper will provide an overview of the experimental aerodynamic characterization of the Ares I vehicle and detail the impacts the experimental program had on the development of the vehicle. It will also discuss the facilities and rationale for choosing specific facilities. In addition, the different experimental test techniques employed in the experimental program will be described.
\end{abstract}

\footnotetext{
${ }^{*}$ Ares Aerodynamics Test Lead, Configuration Aerodynamics Branch, NASA Langley, Senior AIAA Member.

${ }^{\dagger}$ Aerospace Engineer, Configuration Aerodynamics Branch, NASA Langley, Senior AIAA Member.

* Aerospace Engineer, Configuration Aerodynamics Branch, NASA Langley, AIAA Member.

$\S$ Aerospace Engineer, Configuration Aerodynamics Branch, NASA Langley, AIAA Member.
}

1

American Institute of Aeronautics and Astronautics 


\section{Nomenclature}

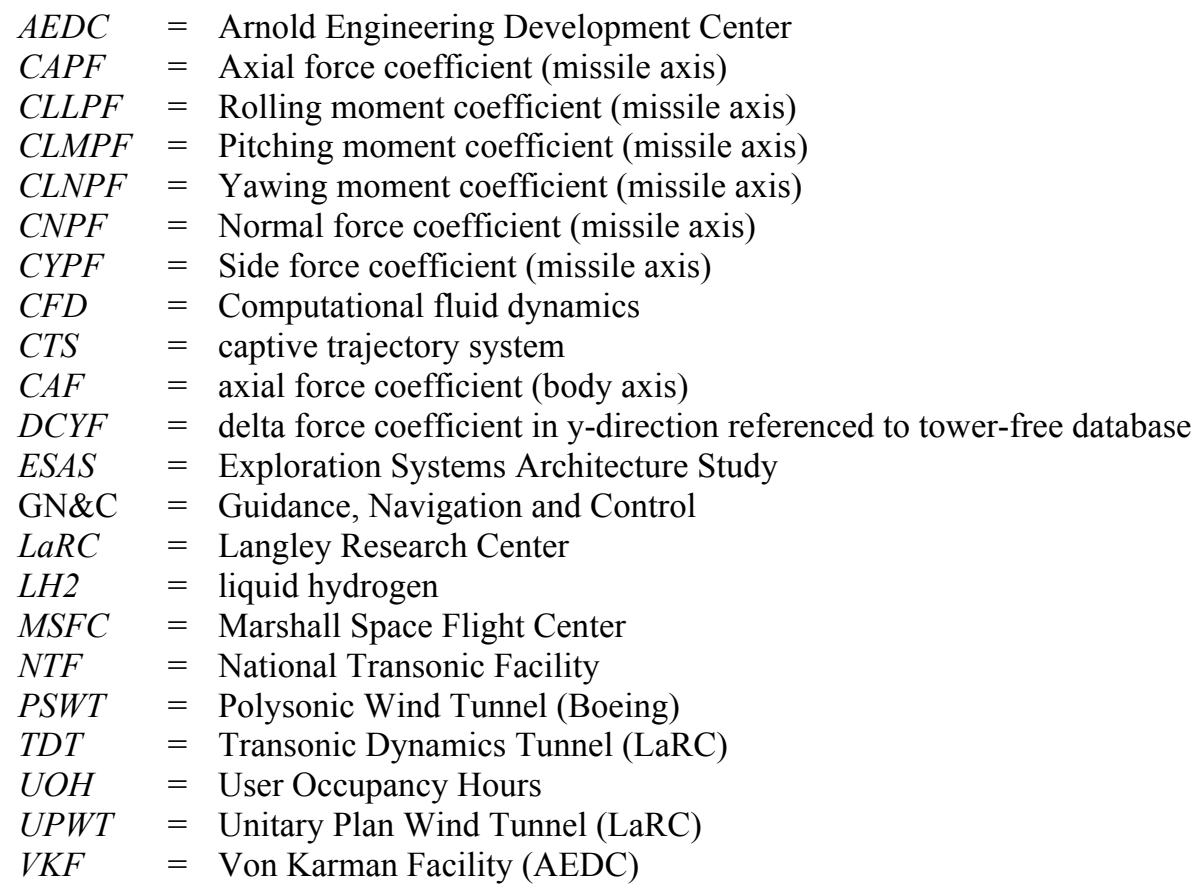

\section{Introduction}

$\mathrm{T}$

HIS document is an overview of the experimental progress that has been undertaken in the development of the Ares I launch vehicle which is a part of the NASA Constellation program. As a representative of the Ares Project, the Ares Aerodynamics Panel has technical oversight of the aerodynamic characterization of the vehicle and directs the Aerodynamics Team in the execution of the test program ${ }^{1}$. The panel is responsible for the delivery of aerodynamic products relating to all flight phases of the vehicle from ground wind loads, transition to ascent, ascent, stage separation, first stage reentry and upper stage aerodynamics. The major customers of the aerodynamic data are the Structures, Loads, Guidance, Navigation and Control, Ascent Performance, Thermal Environments, and Venting disciplines.

As part of the Ares I vehicle development, numerous technical disciplines have been conducting analyses on the architecture to evaluate its mission performance and viability. Since 2005 , an extensive aerodynamic experimental wind tunnel testing program has been conducted for a series of Ares I vehicle configurations as the vehicle design matured. These investigations have utilized multiple aerodynamic research facilities across the United States. A number of varied test techniques have been utilized during Ares aerodynamic characterization experimental investigations.

The aerodynamic characterization of the Ares I vehicle has presented some significant challenges. The length and slenderness of the vehicle, the limited available volume internal to the test articles, the allowable loads, and the complexity of the geometry have contributed to the challenges experienced in the experimental test program. A number of experimental test facilities and test techniques have been utilized in this experimental aerodynamic characterization of the launch vehicle. The selection of the experimental facilities depends on a number of different factors including Mach and Reynolds number capability, type of data required, data accuracy, schedule, and cost of operating the facility. A suite of experimental test facilities has been used to cover the experimental requirements that contain some overlap in test conditions to produce greater confidence in the data as well as provide better experimental uncertainty estimates.

A number of experimental test techniques have been utilized during the experimental test program to date. The majority of wind tunnel testing has included integrated forces and moments for the full-stack vehicle. Also, there have been a series of distributed loads (pressure) tests conducted to provide local vehicle distributions. However, there have been a number of specialized testing approaches that have been used to provide aerodynamic data related to stage separation, lift-off transition and ground wind load tower effects on the launch pad as well as aerodynamic 
heating for vehicle components. This overview paper describes the experimental testing relevant to each of these aspects, present some sample wind tunnel data, and presents impact of the data on the overall vehicle development.

\section{Background}

The Ares I architecture was the design outcome of the Exploration Systems Architecture Study (ESAS) in response to the Vision for Space Exploration challenge provided by President George Bush in 2004. The Ares I vehicle was designed to carry astronauts into low-Earth orbit to support the International Space Station as well as provide transportation to destinations beyond low-Earth orbit including the Moon and Mars. As part of the Ares I vehicle development, numerous technical disciplines have been conducting analyses on the architecture to evaluate its mission performance and viability. As part of the analyses, an extensive aerodynamic characterization effort has been undertaken to evaluate the vehicle. This aerodynamic characterization has included both significant computational fluid dynamics (CFD) efforts and a significant experimental testing phase. The two disciplines have worked together synergistically to provide the aerodynamic characterization required to meet the cost and schedule constraints that were required for the vehicle development.

\section{Flight Phases}

The Ares I architecture is a complex multi-stage vehicle and presents some significant challenges in its aerodynamic characterization. A typical trajectory of the Ares I launch vehicle is shown in figure 1 . The Ares I flight phases and trajectory requires wind tunnel testing at many different Mach numbers and vehicle orientations. For instance, lift-off and ground wind loads testing requires Mach numbers near zero and angles of attack of 90 degrees. The transition from the launch pad to ascent requires testing at Mach numbers between 0 and 0.3 and angles of attack from 0 to 90 degrees. Ascent conditions prescribe a Mach variation from 0.5 to 4.5 and angles of attack generally less than 10 degrees. Stage separation occurs at approximately Mach 5.5 and at angles of attack from 0 to 20 degrees. Reentry of the first stage requires a Mach range from 5.5 to 0 and angles of attack from 0 to 180 degrees whereas the upper stage reentry phase requires testing at hypersonic Mach numbers which the data are used for break-up and range safety concerns. These varied requirements for flight phases and orientations of the vehicle preclude testing in a single experimental test facility and mandates testing in numerous experimental facilities for specific test objectives.

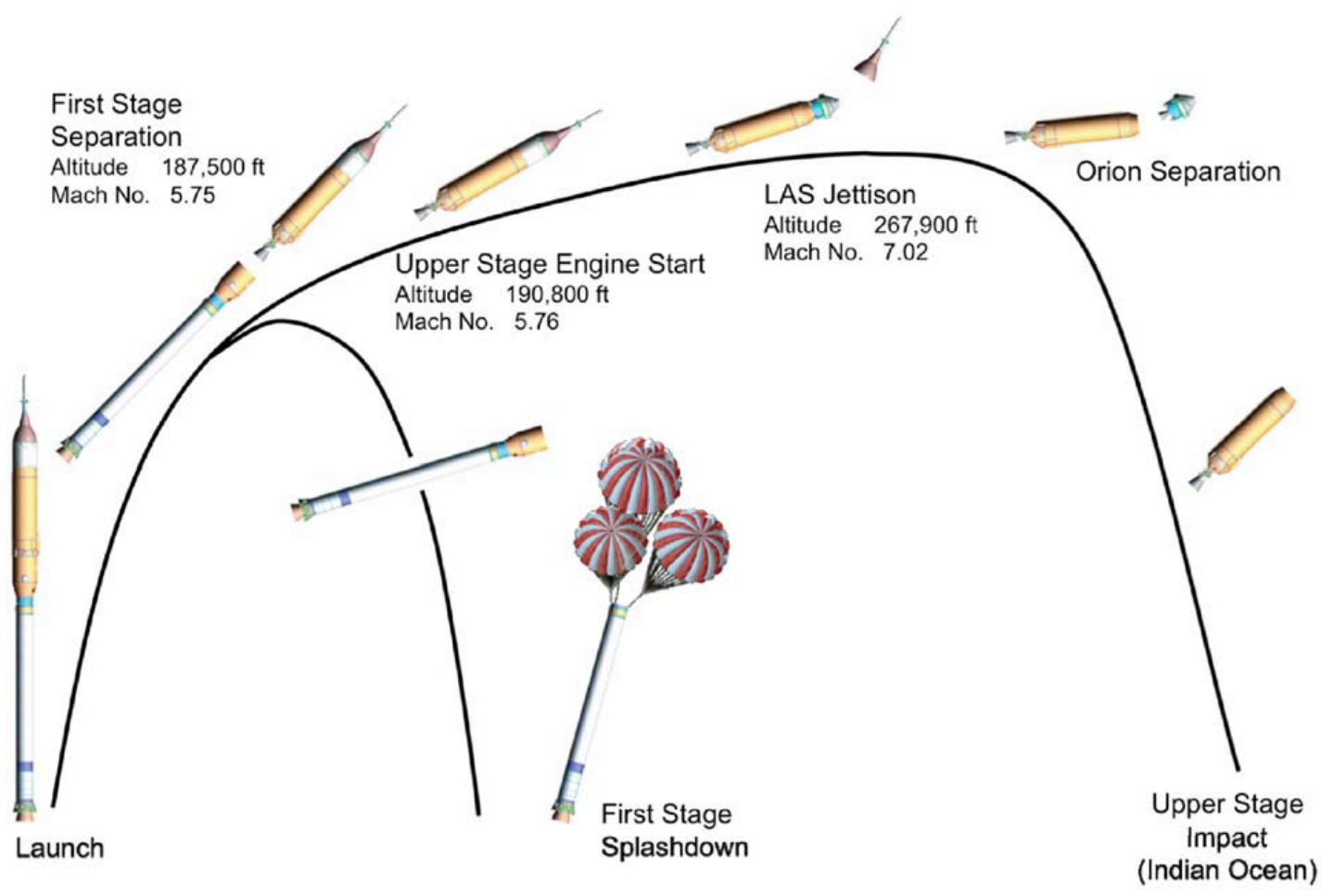

Figure 1. Ares I trajectory. 


\section{Experimental Test Requirements}

The selection of the appropriate experimental test facility depends on various data requirements and constraints. For different phases of the flight envelope, there are different requirements for specific test objectives. For instance, for the subsonic and transonic conditions of the flight, there could be different test objectives with widely different test facilities. Ground wind loads would typically require large models in wind tunnel facilities such as the LaRC Transonic Dynamics Tunnel (TDT) or AEDC 16T that would require the ability to identify aeroelastic effects. For the transition from the launch pad to ascent flight phase, the facility must be able to test at angles of attack from 0 to 90 degrees. In this phase of flight, Reynolds number effects may be significant so this would need to be considered in the test planning. For the full-stack during ascent, a limited angle of attack range would be required typically, but Reynolds numbers could be two orders of magnitude less in a conventional test facility as compared to flight. Even in a cryogenic test facility such as the LaRC National Transonic Facility (NTF), the Reynolds number would still about 3 to 9 times lower than the flight value as shown in figure 2. For first stage reentry, a large angle of attack range from 0 to 180 degrees is required and typically would be tested in smaller test facilities.

For supersonic conditions specialized requirements are needed. For full-stack ascent testing, typically only small-scale facilities are available since some of the large supersonic facilities have been decommissioned. For conditions near the maximum dynamic pressure of the Ares I vehicle, Reynolds numbers would be 30 to 100 times lower than flight conditions. For first stage reentry testing, a large range of angle of attack is required which requires multiple model support arrangements inside the facility.

For hypersonic conditions, first stage reentry testing would typically require a small facility and small-scale test article based on the large Mach range and angle of attack data requirement. Stage separation testing typically requires two force/moment balances, a large variety of model orientations, and is typically best be accomplished with a captive trajectory system to provide the needed proximity aerodynamics interaction effects. Upper stage testing at hypersonic conditions would require a large angle of attack range for upper stage tumbling simulations.

As described here, there are numerous wind tunnel model and facility requirements and constraints that are dictated by the specific test objectives and flow conditions for the experimental program. The choice and rationale for each facility for the Ares I program was dependent on facility capability as well data requirements, cost and schedule constraints. Some of the facilities are described below.

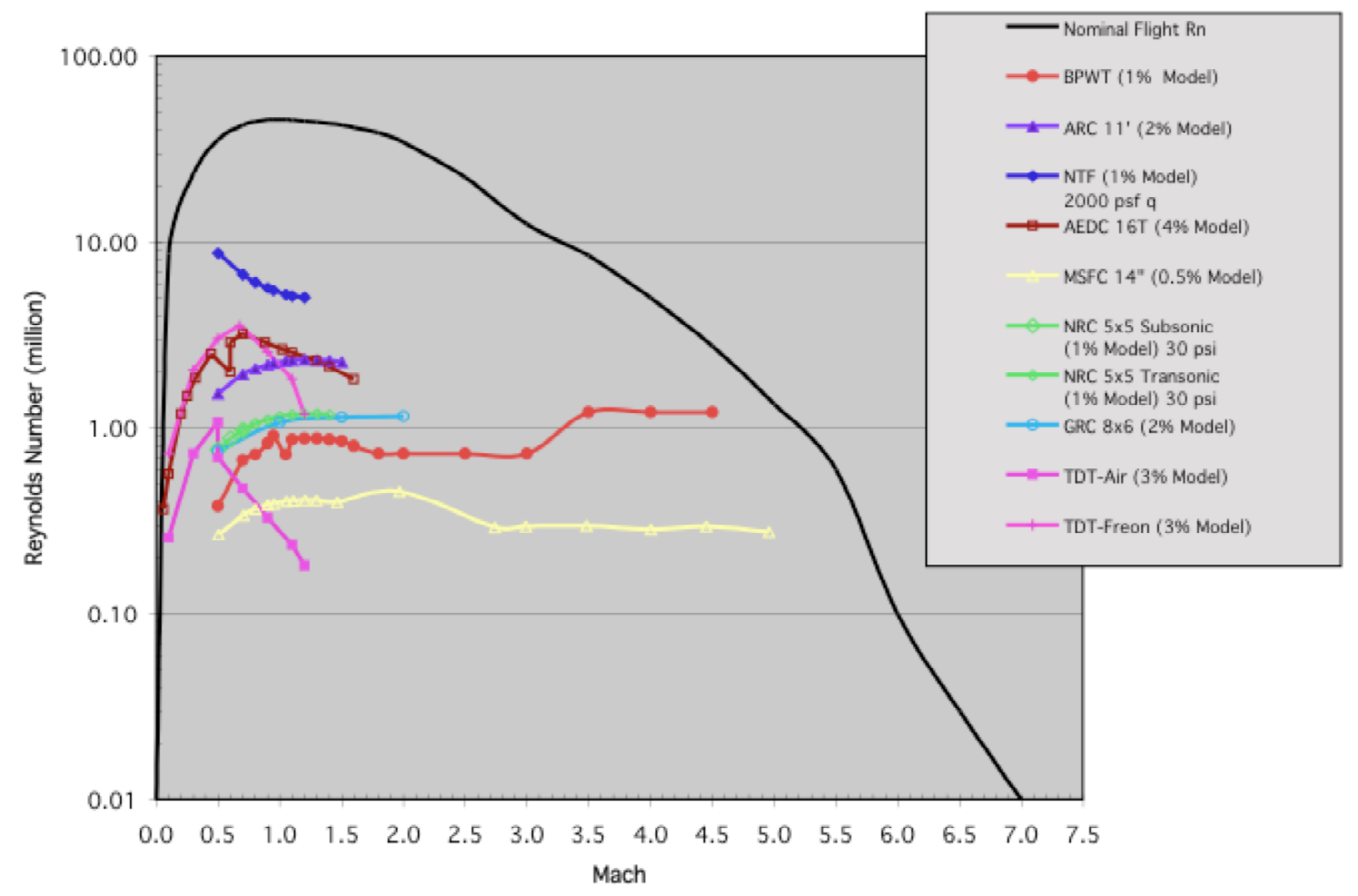

Figure 2. Test envelopes of subsonic and transonic wind tunnels. 


\section{Facilities}

The Ares Aerodynamics Team has attempted to utilize the appropriate experimental facilities that best suit the test objectives while providing high quality and timely aerodynamic data. The main facilities that the Aerodynamics Team utilized have included the MSFC 14 inch Trisonic Tunnel, the LaRC Unitary Plan Wind Tunnel (UPWT) ${ }^{2}$, and the Boeing Polysonic Wind Tunnel. These are the three main experimental facilities that have produced the majority of the data required for the full-stack ascent aerodynamic characterization as well as the first stage reentry aerodynamics characterization.

Other facilities that have been utilized for specialized testing requirements have included the LaRC National Transonic Facility (NTF), the LaRC Transonic Dynamics Tunnel (TDT), the Arnold Engineering and Development Center (AEDC) Von Karman Facilities, the LaRC 20 inch Mach 6 Tunnel, the LaRC 14X22 Low Speed Wind Tunnel and the LaRC Mach 6 CF4 and Mach 10 Aerothermodynamic Facilities.

These tunnels have been judged by the Aerodynamics Panel to provide a high quality of aerodynamic data within the budget constraints provided by the project. The two main 4 foot facilities (UPWT and PSWT) also have some overlap in their Mach number capabilities around the expected maximum dynamic pressure for the Ares I trajectory and have proven to provide the necessary uncertainty bounds for the aerodynamic databases. A few other facilities have been tested by the Aerodynamics Team with various Ares configurations but have not provided the required capabilities or the data quality required.

A summary of all of the wind tunnel testing for Ares development to date is shown in Table 1. The table is broken down into ascent testing (which includes stage separation) and descent testing for the Ares I first stage. The experimental program has required over 8000 user occupancy hours (UOH) in the wind tunnel facilities to date.

\begin{tabular}{|c|c|c|c|}
\hline Ascent & Total & Descent & Total \\
\hline Ascent Testing Roundup & 6069.25 & Descent Testing Roundup & 2376 \\
\hline ARF & บон & ARF & UOH \\
\hline CLV Rev 4 & 120 & Low alpha FS reentry & 232 \\
\hline DAC-0 5.5m US & 72 & FS Descent Database & 536 \\
\hline CLV Rev 4.2 & 88 & ASA Baroswitch (1st stage) & 288 \\
\hline $1.5 \%$ DAC- 1 LAS & 56 & Nozzle Extension Increment test & 104 \\
\hline $1.0 \%$ DAC-1 LAS & 88 & 10 BDM Increnment Test & 120 \\
\hline Horowitz LAS Concept & 32 & 8 BDM Increment Test & 88 \\
\hline DAC-0 6.5m US & 40 & First Stage Pressure Test & 320 \\
\hline LAS Parametric & 96 & First Stage Parametrics (Thruster Pod $\varepsilon$ & 40 \\
\hline CEV CRC3 & 64 & First Stage Reentry Test & 200 \\
\hline DAC-1 & 16 & LaRC 20" Mach 6 & \\
\hline Pre DAC-2 & 32 & $.65 \%$ FS Descent & 328 \\
\hline Post Abort Stack & 48 & PSWT & \\
\hline DAC-1/PreDAC-2 repeat & 40 & First Stage Wall Intereference Test & 120 \\
\hline Ares $1-X$ Post Sep & 40 & & \\
\hline Ares 1-X Post Sep2 & 24 & & \\
\hline UPWT & & & \\
\hline $0.5 \%$ CLV Rev 4.2 & 128 & & \\
\hline $1 \%$ ADAC- 1 F\&M & 72 & & \\
\hline $1 \%$ Clean ADAC-1 Pressure Model & 544 & & \\
\hline 1\% ADAC-2A F\&M (Including ALAS-11) & 336 & & \\
\hline Ares 1-X Stage Separation studies & 433.5 & & \\
\hline ADAC-2B A103 & 167.25 & & \\
\hline A106 1\% Force and Moment Test & 240 & & \\
\hline PSWT & & & \\
\hline DAC-1 Force \& Moment & 88 & & \\
\hline DAC-1 Pressure & 616 & & \\
\hline DAC-1, 605, ALAS-1, -2, \& -3 Force \& Mom. & 40 & & \\
\hline DAC-2 \& ALAS-11 Force \& Moment & 120 & & \\
\hline ADAC-2B A103 F\&M & 64 & & \\
\hline ADAC-2B A103 Pressure & 168 & & \\
\hline A106 1\% Force and Moment Test & 150 & & \\
\hline ARC & & & \\
\hline CLV Rev 4.2 & 37 & & \\
\hline Dynamic Damper & 54.5 & & \\
\hline TDT & & & \\
\hline Ares I (DAC-1) GWL Checkout Model & 224 & & \\
\hline Ares I-X Rigid Buffet Model & 384 & & \\
\hline Ares I-X GWL Model & 448 & & \\
\hline Ares I Rigid Buffet Model & 352 & & \\
\hline NTF & & & \\
\hline ADAC-2B A103 Pressure & 141 & & \\
\hline AEDC & & & \\
\hline $1 \%$ Stage Separation (Ares I-X+Ares I) & 131 & & \\
\hline A103 Strake Test & 22 & & \\
\hline $14 \times 22$ & & & \\
\hline A106 Lift-Off Transition & 133 & & \\
\hline Mach 6 CF4 and Mach 10 & & & \\
\hline Aeroheating & 120 & & \\
\hline
\end{tabular}

Table 1. Summary of Ares I wind tunnel testing.

American Institute of Aeronautics and Astronautics 


\section{Test Techniques}

There have been a number of test techniques utilized so far in the Ares aerodynamic database development. Static forces and moments with six degrees of freedom using internal strain gauge balances have provided the majority of the primary databases for use by the different vehicle disciplines. Load distributions have also been provided with the use of distributed static pressures in a few Ares design cycle variations. These pressure models are limited to approximately 200 static pressures based on available volume internal to the test article. Static pressures have been primarily located along the top vehicle centerline. Static pressures are also located coarsely on constant cross sectional areas and at finer spacings along varying diameter sections (cones and flares). Symmetry is utilized to provide load distributions for clean configurations (no protuberances) by rolling the test article from 0 to 180 degrees in distinct increments. For the full protuberance configurations, localized pressures are installed near large protuberances, such as the liquid hydrogen (LH2) feedline fairing, to obtain interaction effects as shown in figure 3. These experimental static pressure locations were guided by pre-test computational results. Computational fluid dynamics provide load distributions for asymmetric configurations as there would not be enough static pressure ports on a $1 \%$ scale model to provide these detailed load distributions. Reynolds number effects testing have been evaluated on a $1 \%$ pressure model in the cryogenic test medium of the National Transonic Facility at LaRC. In general, Reynolds number effects were not significant on normal load distributions for limited Mach numbers available in the NTF. However, flight Reynolds numbers were not achievable in the subsonic/transonic facility so a complete Reynolds number analysis is not yet available. Reynolds number effects on 6 degree-of-freedom integrated loads have not been addressed yet. In addition, wall interference effects, unsteady pressure and buffeting tests, and an aeroheating effects test utilizing ceramic models have been conducted to date.

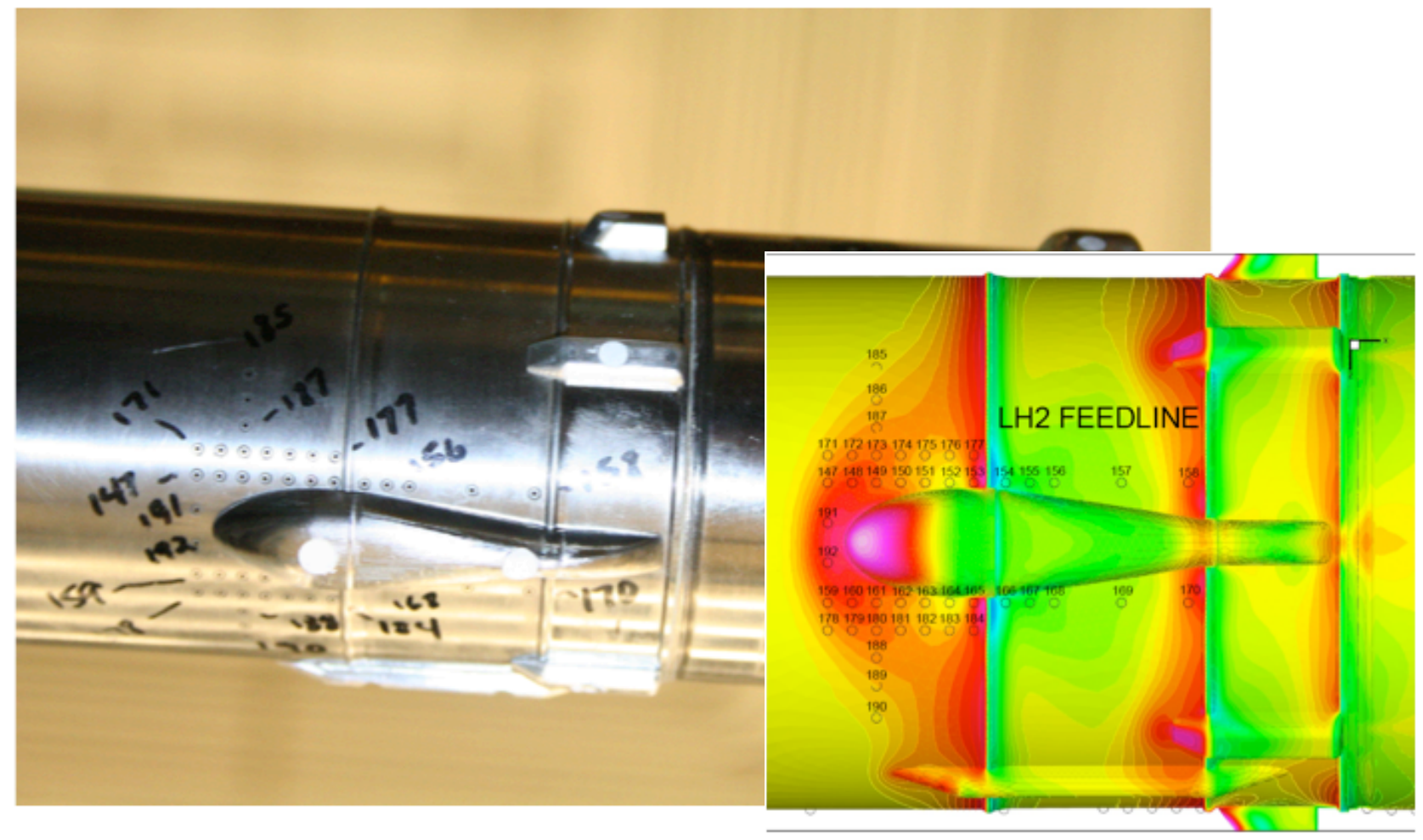

Figure 3. Localized surface static pressure locations in vicinity of LH2 feedline fairing (guided by CFD). 


\section{Experimental Results}

The following experimental results are representative of the type of wind tunnel testing and test techniques utilized in the experimental program for the Ares I launch vehicle. This is not a complete detailed experimental program description but is intended to show the variety of aerodynamic characterization wind tunnel activities and the subsequent effect on the Ares I vehicle development.

\section{Ascent Tests}

The majority of experimental investigations have been conducted on the full-stack configuration for the ascent portion of the flight trajectory of the Ares I. These tests have been primarily conducted in the Boeing PSWT for subsonic and transonic regimes and in the LaRC UPWT for the supersonic regimes of flight. For proper sizing in these 4 foot square test sections, the size of the model was limited to $1 \%$ scale. A typical Ares I model is shown installed in the Boeing PSWT test section in figure 4.

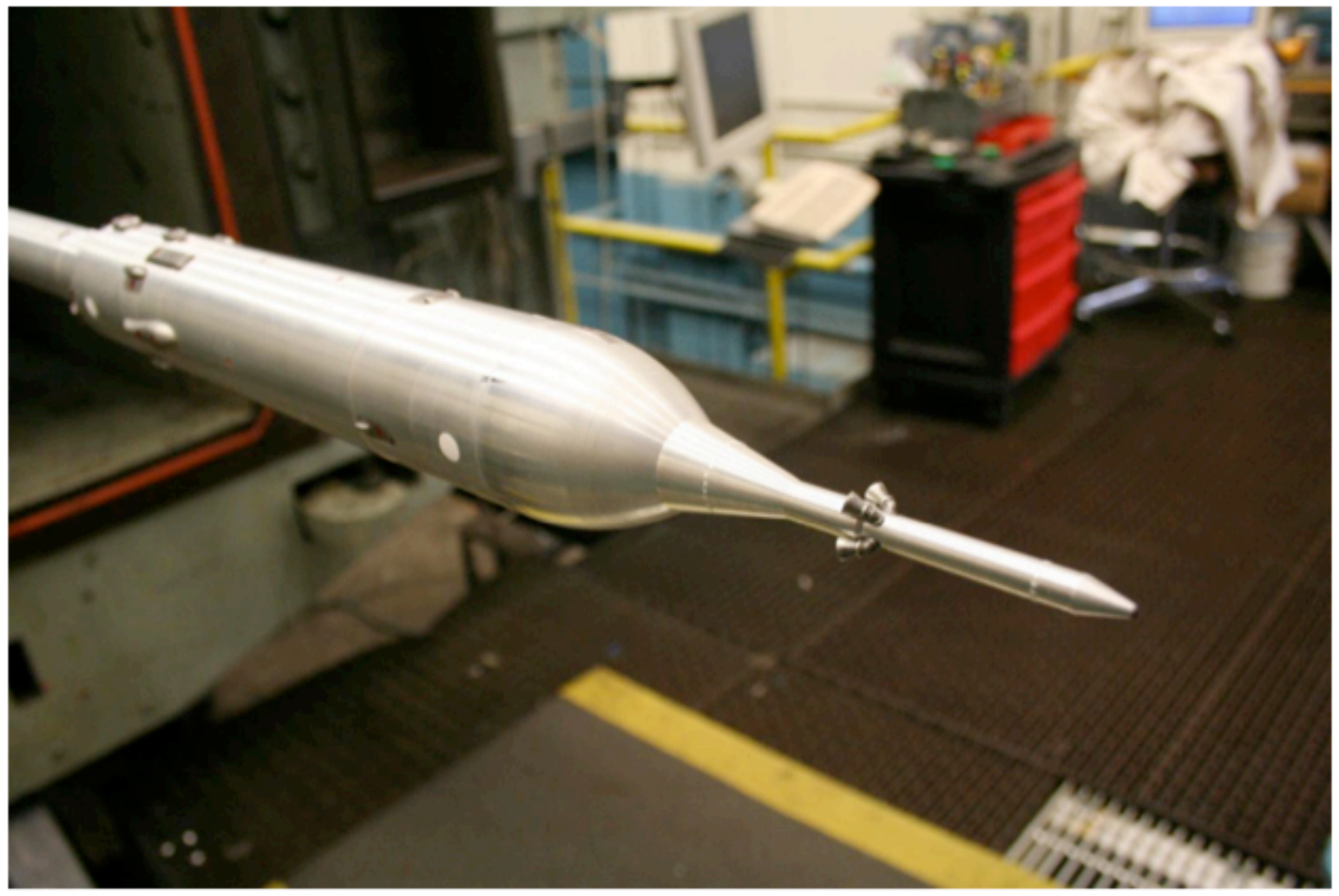

Figure 4. Ares I force/moment model installed in Boeing Polysonic Wind Tunnel. 
The two major configurations tested were the model with all external protuberances installed as shown in figure 5 and the model in the "clean" configuration with all of the external protuberances removed as shown in figure 6. The purpose of testing the model in the clean configuration, across the entire Mach number range, was to provide a reference and produce an incremental database for the integrated forces and moments by removing systematic error and bias. The clean configuration, while expected to be symmetric, produces a bias that is measureable in the experimental test facillity. This effect may be as a result of flow asymmetries or model fidelity/machining accuracy. This bias is then subtracted from the clean configuration to produce a better overall incremental aerodynamic database. Some sample results, obtained from the Boeing PSWT for the full protuberance configuration, are shown in figure 7. These experimental integrated results are shown as compared to pre-test computational results. In general, results are comparable with computational results except for axial force (CAF). Experimental results have typically shown a higher axial force than the pre-test predictions which is significantly outside the experimental uncertainty. In addition to integated forces and moments, flow visualization data have been obtained from ascent experimental tests. A sample Schlieren photograph is shown in figure 8. This photo shows the density gradients for the full protuberance configuration and the effects these protuberances have on the flow field at supersonic Mach numbers. These integrated force and moment ascent tests provided critical aerodynamic data to the Ares I GN\&C and Ascent Performance disciplines to enable controlled flight and performance metrics for mission requirements.

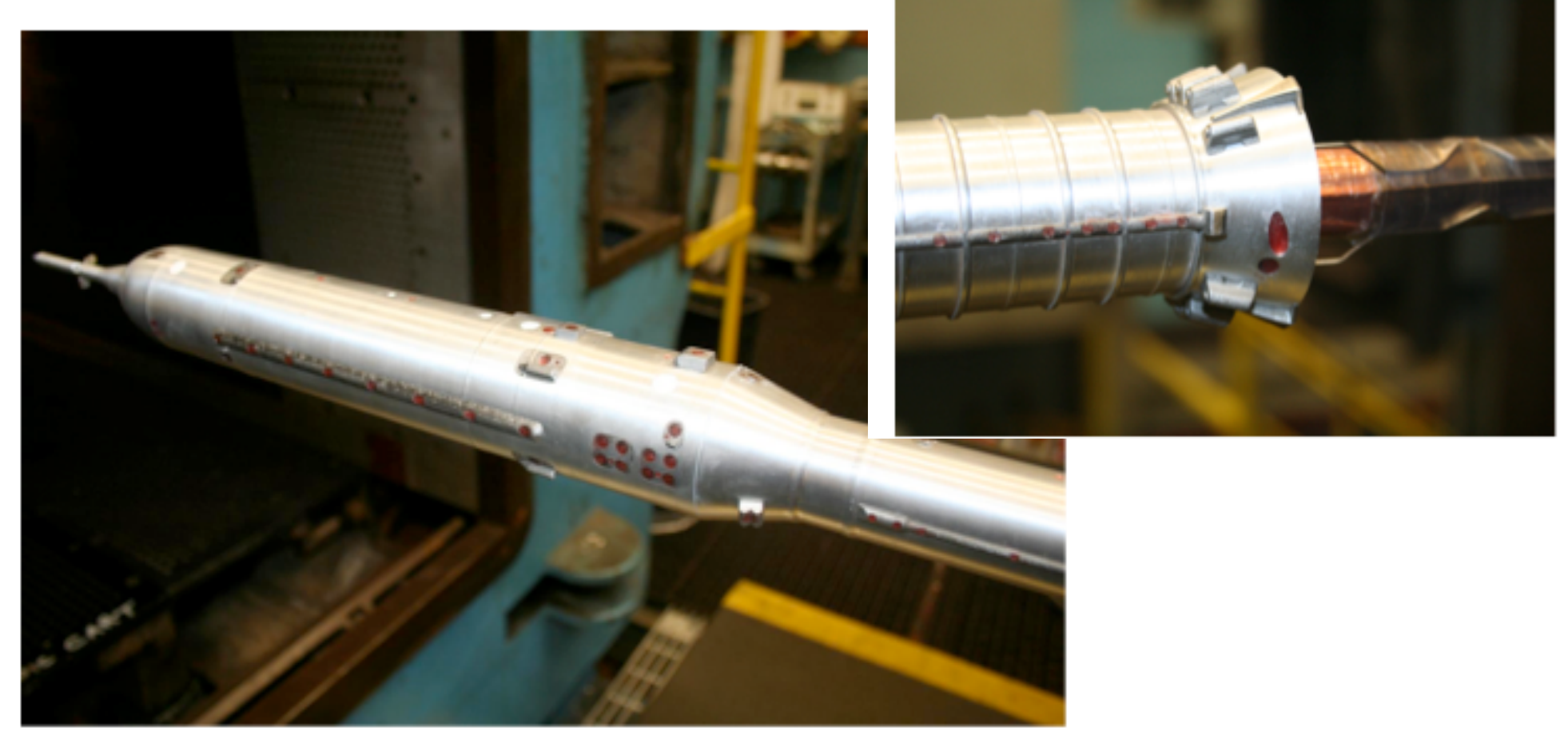

Figure 5. Ares I full protuberance configuration. 


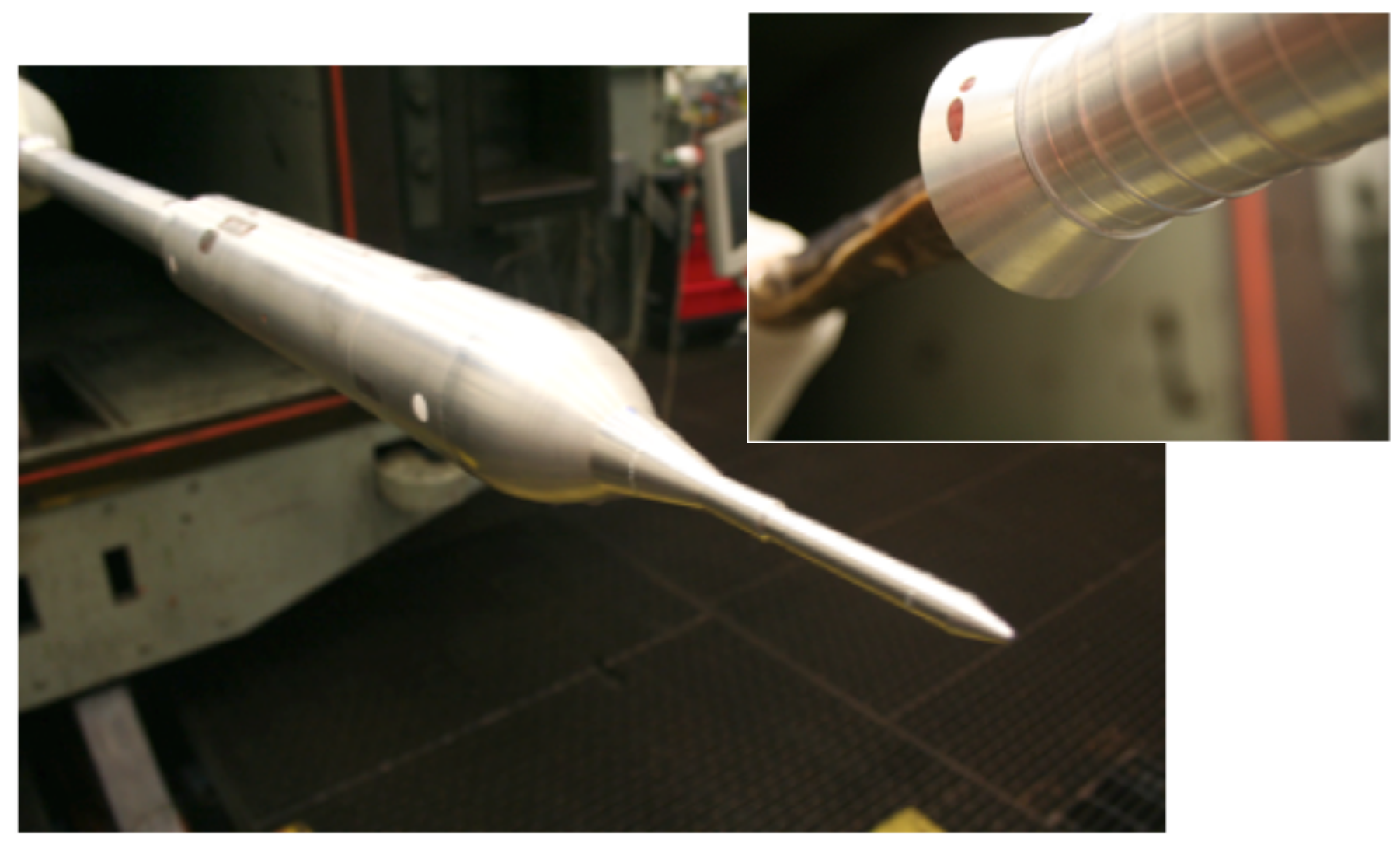

Figure 6. Ares I clean configuration.
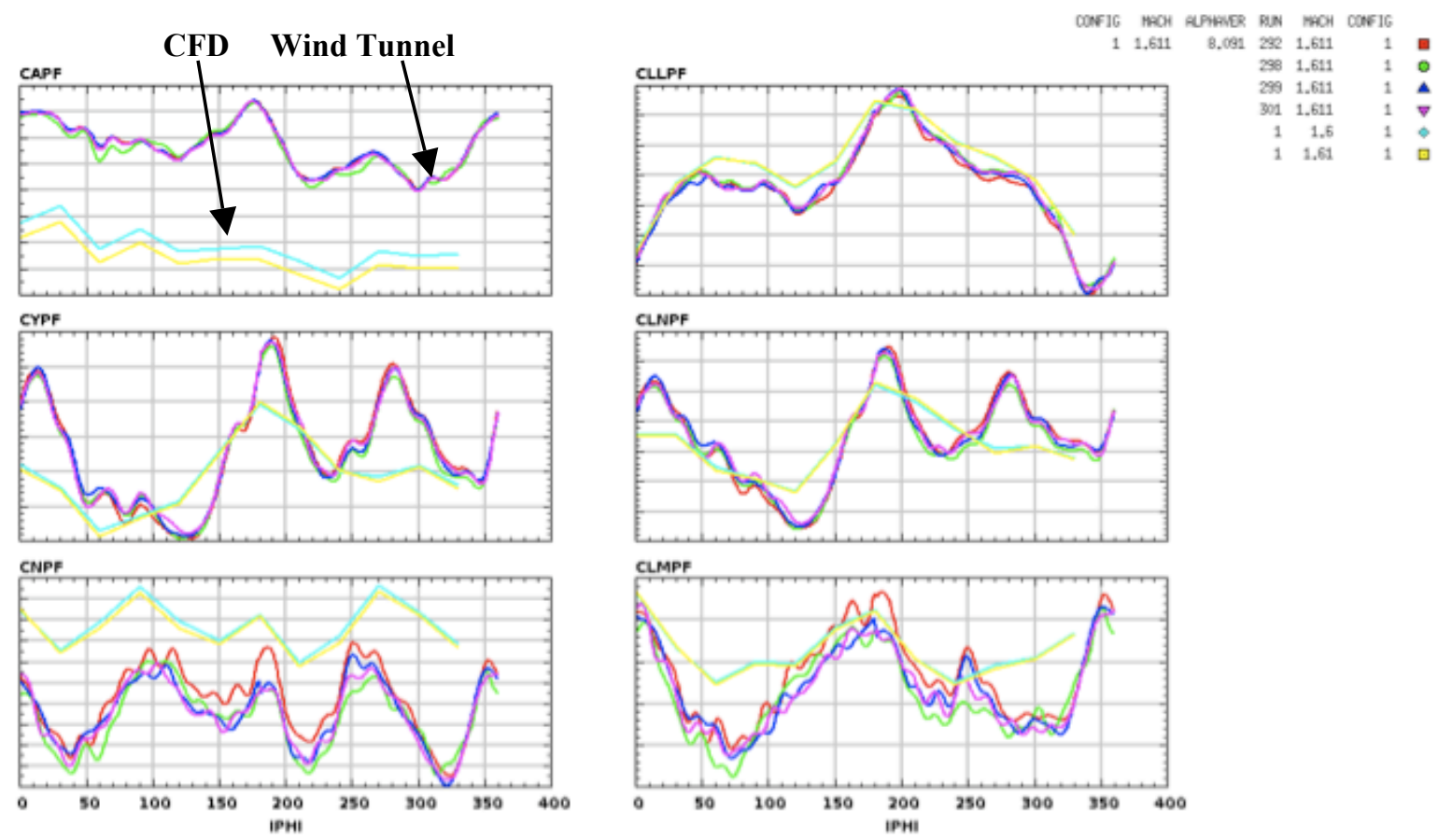

Figure 7. Wind tunnel to CFD integrated force/moment comparisons for Ares I model obtained in Boeing PSWT at $\mathrm{M}=1.61$. 


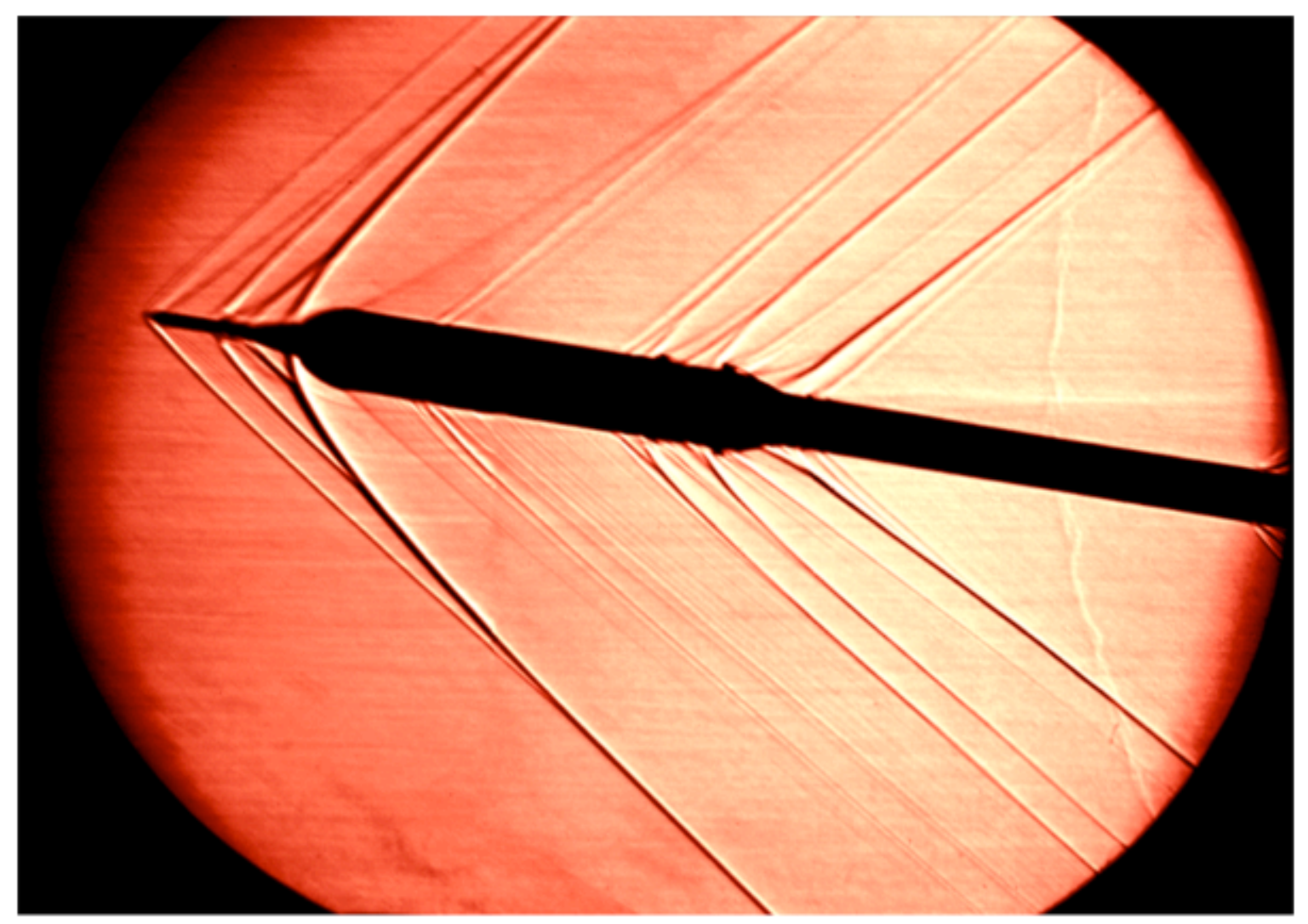

Figure 8. Schlieren photograph of Ares I model full protuberance configuration at $\mathrm{M}=1.61$, alpha $=8 \mathrm{deg}$.

\section{Pressure Tests}

A number of Ares models, instrumented with steady pressure transducers, have also been tested in the same experimental facilities (Boeing PSWT, UPWT) as the integrated force/moment testing. A single NTF pressure test was conducted, but a similar force/moment test has not been conducted to acquire Reynolds number effects on integrated loads. As previously mentioned, model scale was limited to $1 \%$ for pressure testing based on sizing contraints. As a result of this scale model size, the maximum number of steady pressure transducers was limited to about 200 sensors installed in the model. The purpose of these pressure tests was to provide normal load distributions for validating computational predicted loads. A sample of a comparison between the experimental results and the pre-test computational distributed loads is shown in figure 9 with the symbols representing the experimental results ${ }^{3}$. These experimental results compare very favorably with the computational results along the length of the vehicle for the clean configuration. Since there was not enough volume internal to the model to adequately provide distributed load distributions for the full protuberance configuration, all of the distributed load validations were conducted in the clean configuration. However, there were localized effects around protuberances that were validated (see figure 3) for the full protuberance configuration. In general, pre-test compuational results were validated with experimental results around selected large protuberances. CFD best practices for launch vehicles benefited significantly with this set of experimental validation pressure and loads data. 


\section{$\Delta \mathrm{C}_{\mathrm{N}} /(\Delta \mathrm{x} / \mathrm{D})$}

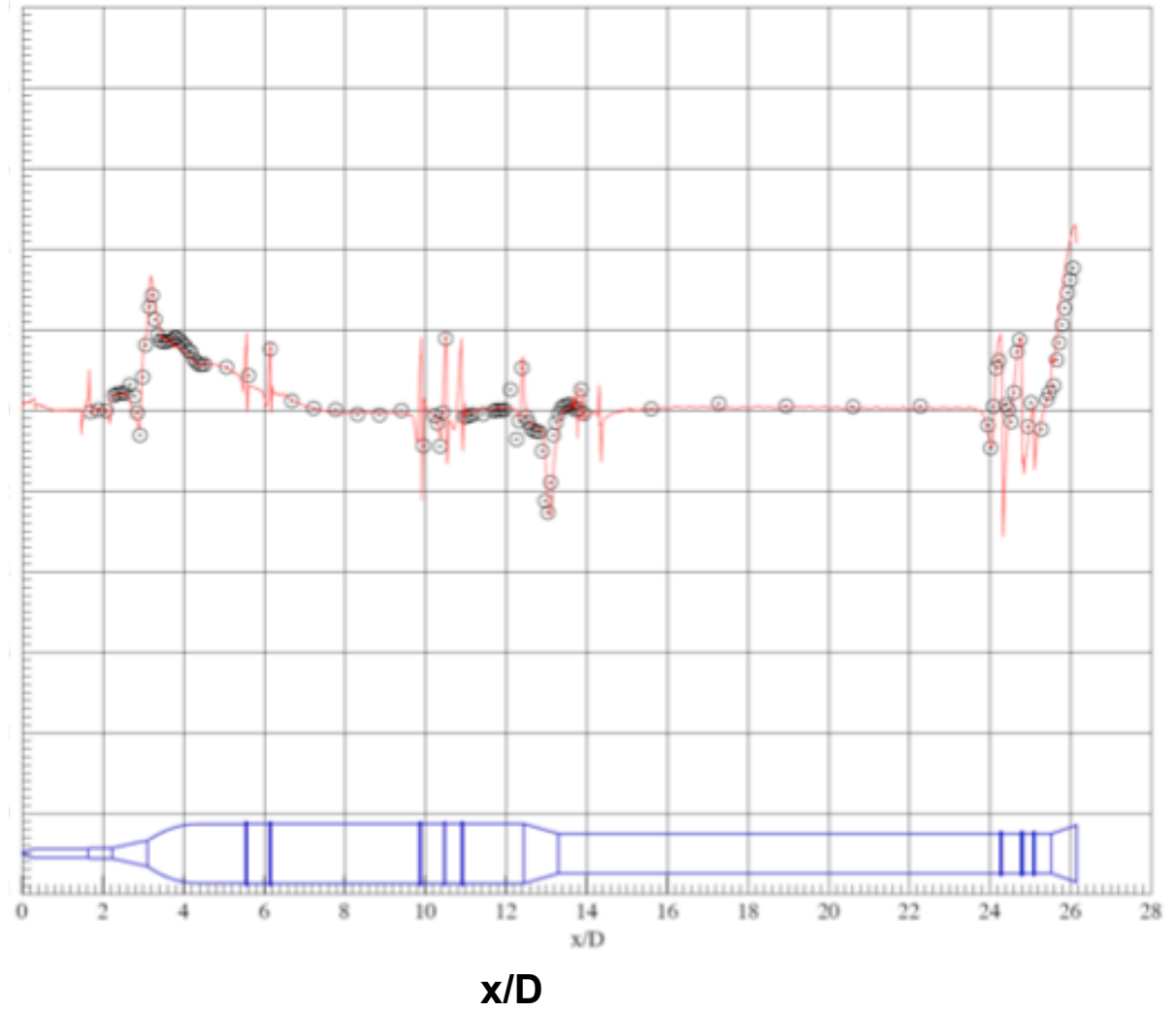

Figure 9. Comparison of wind tunnel to CFD load distributions for Ares I at M=1.6 and alpha $=7 \mathrm{deg}$.

\section{Liftoff / Transition Test}

Another experimental investigation was conducted to evaluate ground wind loads, launch tower effects, and transition aerodynamics from liftoff to ascent flight. This test was conducted in the LaRC 14X22 Low-Speed Wind Tunnel. The risk of the Ares I vehicle drifting into the tower during liftoff has been a concern for the project, and some Monte Carlo analyses had shown this to be of major concern to the project ${ }^{4}$. This test was conducted to provide a better aerodynamic database for this simulation. The test was conducted in a number of phases and had a number of planned test objectives. The major objective of the test was to evaluate launch tower interaction effects on the aerodynamics of the vehicle. The wind direction on the vehicle and tower was using a ground turntable that rotated to change the direction of the wind relative to the vehicle and tower. In addition, the model could be translated vertically to simulate the vehicle starting liftoff and eventually clearing the tower. The test setup in the $14 \mathrm{X} 22$ facility is shown in figure 10. The results from this test, as shown in figure 11, highlight the effect of the blockage of the tower on the side force (+ force pushing the vehicle into the tower) relative to a tower-free configuration as well as the effect of the location of the vehicle as the vehicle begins to clear the tower. These aerodynamic results have significantly reduced the risk the project retains as to vehicle drift concerns since the aerodynamic proximity effects obtained in the test were reduced by as much as $40 \%$ as compared to engineering estimates and legacy space shuttle aerodynamic effects used in previous Monte Carlo simulations. In addition to the liftoff data, an additional objective of the test was to provide a database between the ground wind loads dataset $(M=0)$ and the ascent dataset $(M=0.5)$. This portion of the test was conducted at varying angles of attack up to 90 degrees, at varying roll angles, and has provided a more refined aerodynamic dataset for use by the Guidance, Navigation, and Control disciplines as had been previously modeled. 


$$
\begin{aligned}
\text { Height } & =0 \text { in }, \\
h / L & =0
\end{aligned}
$$
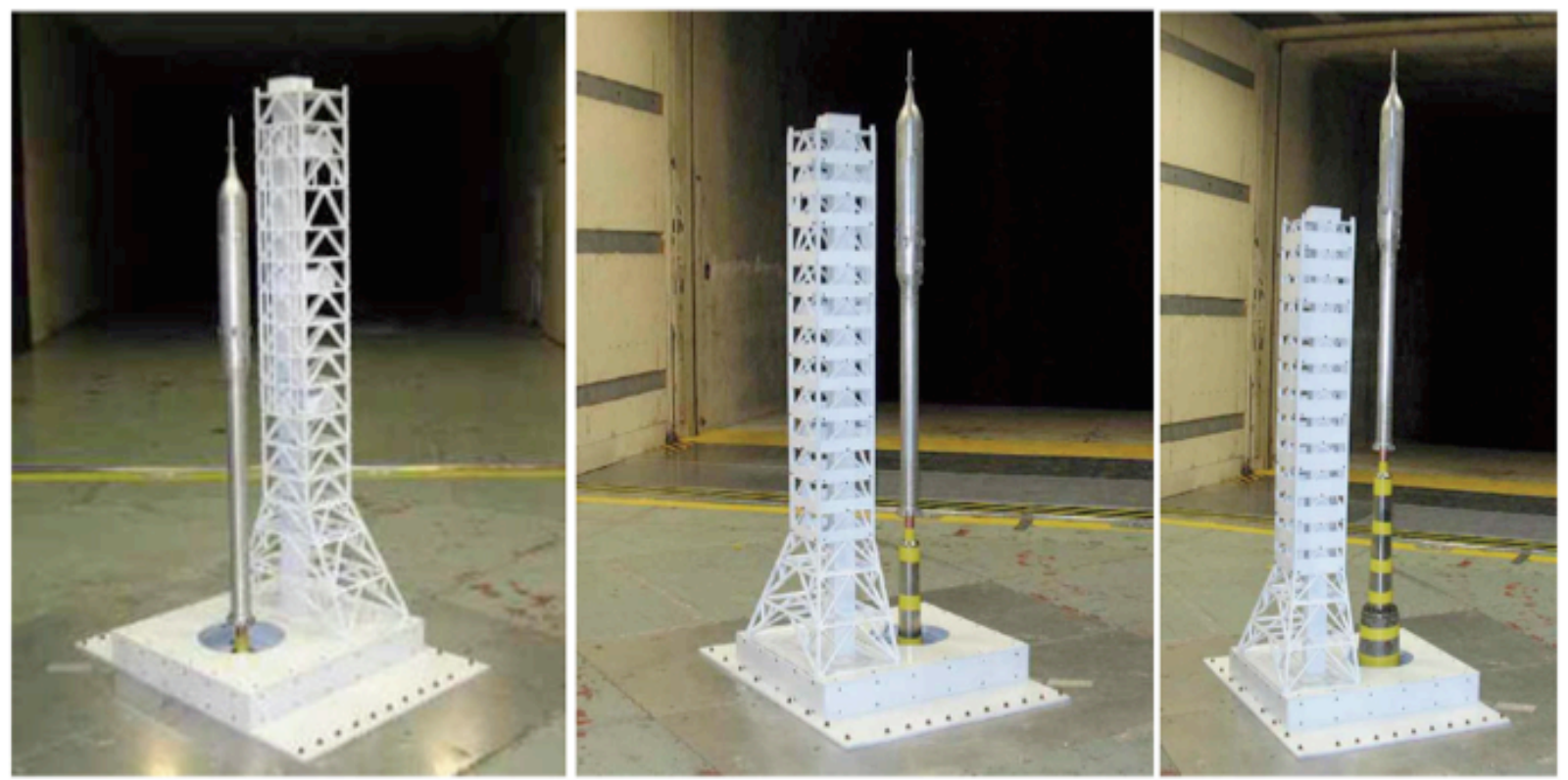

Figure 10. Liftoff / Transition model installed in 14X22 Low Speed Wind Tunnel.

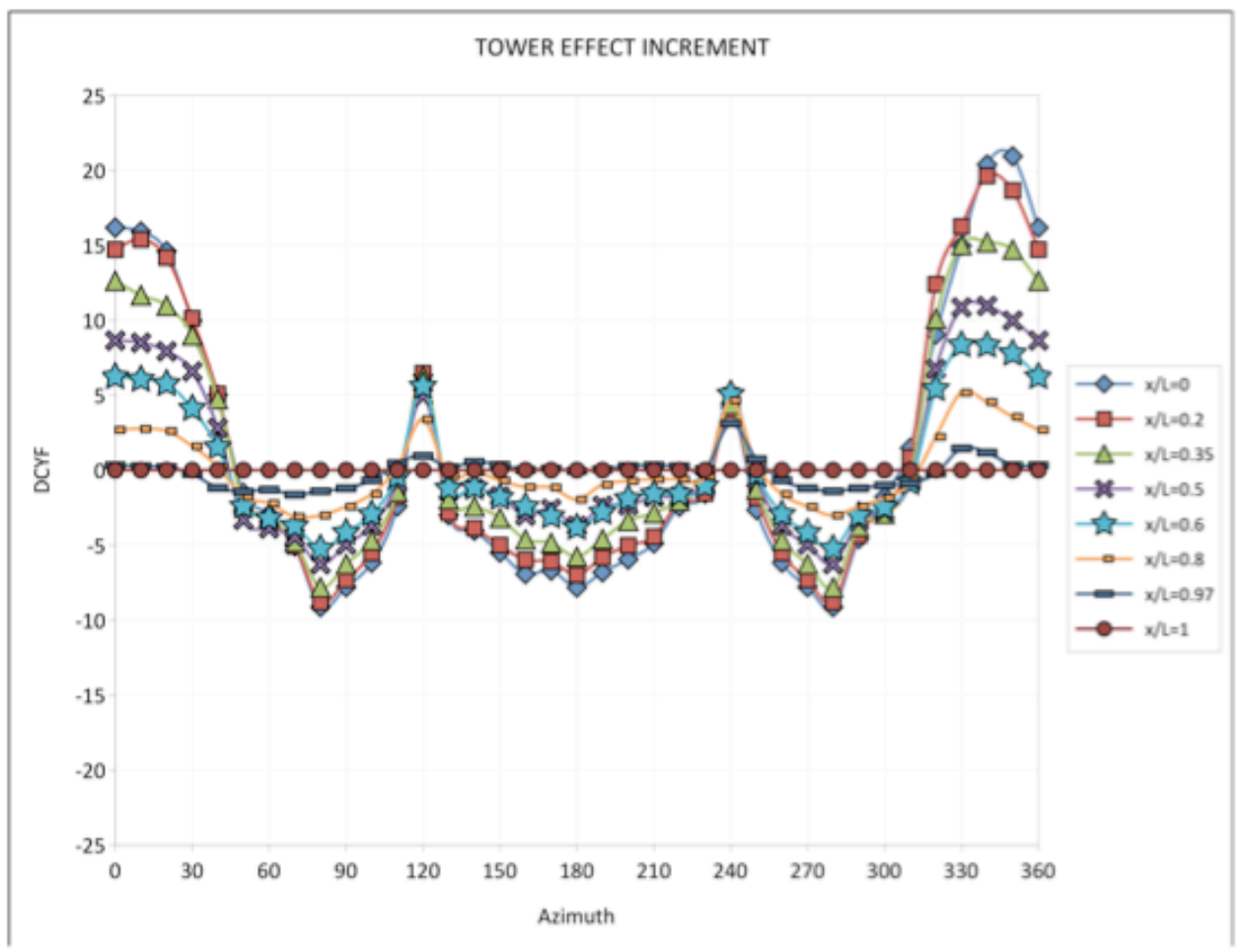

Figure 11. Tower effect increments of Ares I model in 14X22 Low Speed Wind Tunnel. 


\section{Stage Separation Tests}

Another concern for the vehicle during its design trajectory was the separation of the first stage solid rocket booster from the upper stage component after it had depleted its solid fuel propellant. There has been some concern about the interstage of the first stage from clearing the nozzle of the $\mathrm{J} 2$ - $\mathrm{X}$ engine. A detailed separation aerodynamic wind tunnel investigation was conducted in the AEDC VKF Tunnel A to help to investigate the interaction aerodynamic effects ${ }^{5}$. A comparison of the separation plane details between the Ares I architecture and the Ares I-X demonstration flight architecture is shown in figure 12. The Ares I design requires a more complex separation sequence and requires better control in order to avoid contact with the nozzle of the upper stage engine. The interstage, which houses the J2-X engine for the Ares I vehicle, must be able to separate cleanly to avoid contact of the J2-X engine. There is only about approximately 18 inches of buffer inside the interstage on each size of the nozzle so this is a challenging controlled separation event. This complex experimental investigation required two separate Ares I models (upper stage and first stage with interstage attached) with independent strain gauge balances installed in each model. It also required the Captive Trajectory System (CTS) that was needed to precisely locate the components in space relative to each other to fill out the planned test matrix. The model setup in the AEDC VKF Tunnel A is shown in figure 13. The CTS remotely positioned the first stage at the required $\mathrm{x}, \mathrm{y}$, and $\mathrm{z}$ positions and was able to provide interactions within 0.2" of the upper stage. A sample of the axial force on the first stage booster is shown in figure 14. These results, as a function of separation distance between the two stages, are compared to pre-test CFD results. Since this is a very challenging, highly unsteady flow field for CFD to correctly model, the experimental results have been utilized by GN\&C discipline to more accurately represent the interaction aerodynamics. In addition to the integrated forces and moments obtained from the test, flow visualization data was obtained from this test in the form of Schlieren photographs, as shown in figure 15, which show the shock structure and interaction effects after the two stages separate during flight. This separation test was crucial in the successful flight test of the Ares I-X vehicle and provided the GN\&C discipline with the unpowered proximity aerodynamic effect for a separation of the Ares I vehicle.

\section{Ares I-X}
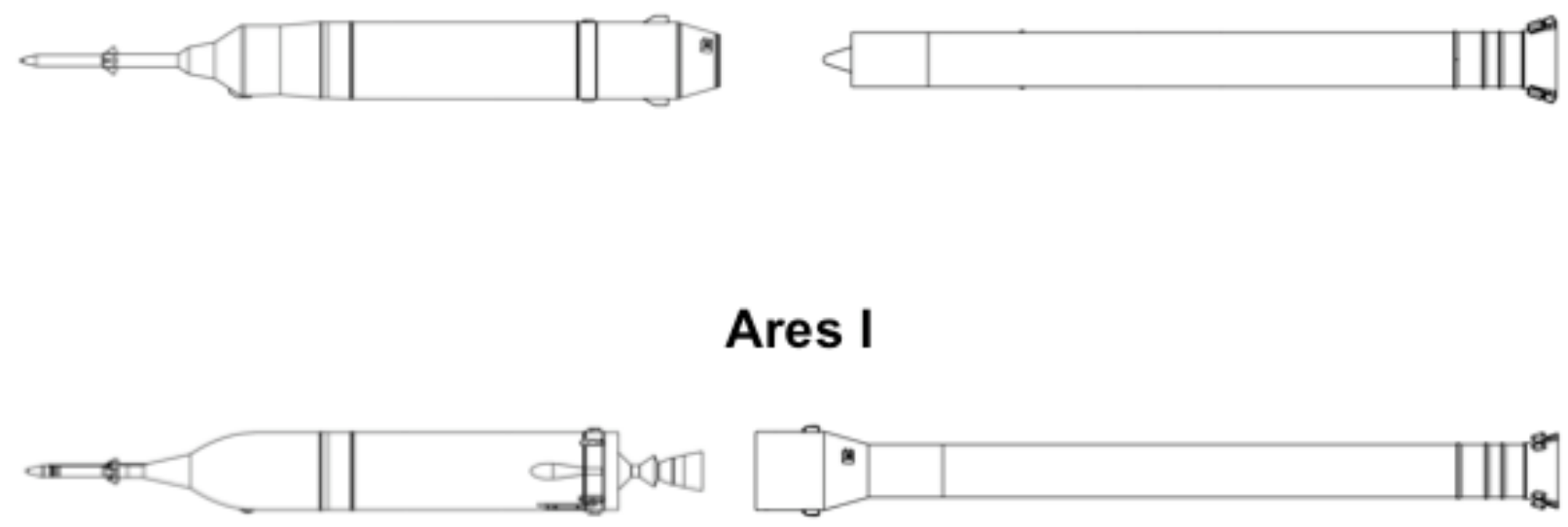

Figure 12. Comparison of Ares I-X and Ares I separation planes. 


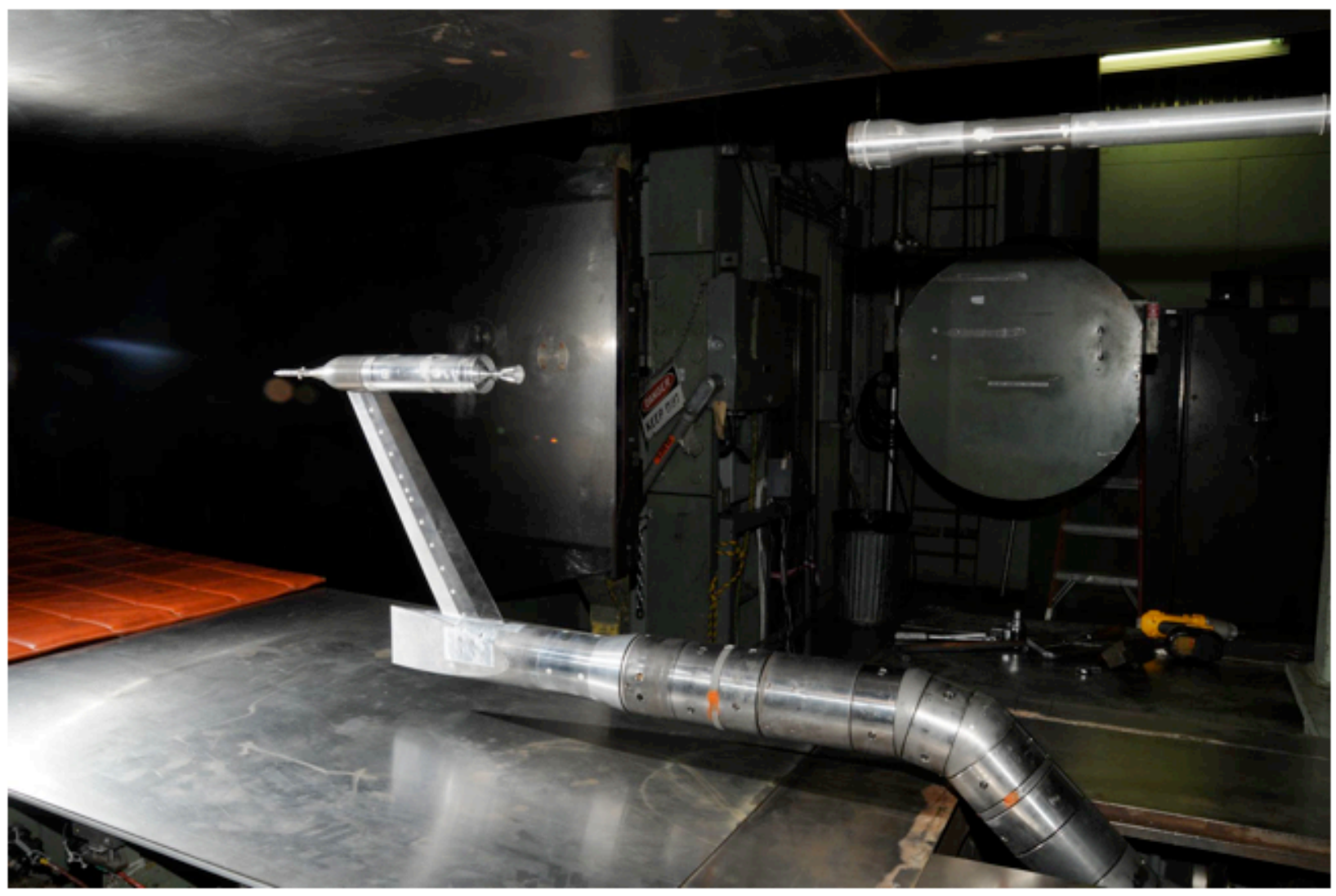

Figure 13. Ares I stage separation test in AEDC Von Karman Tunnel A facility.

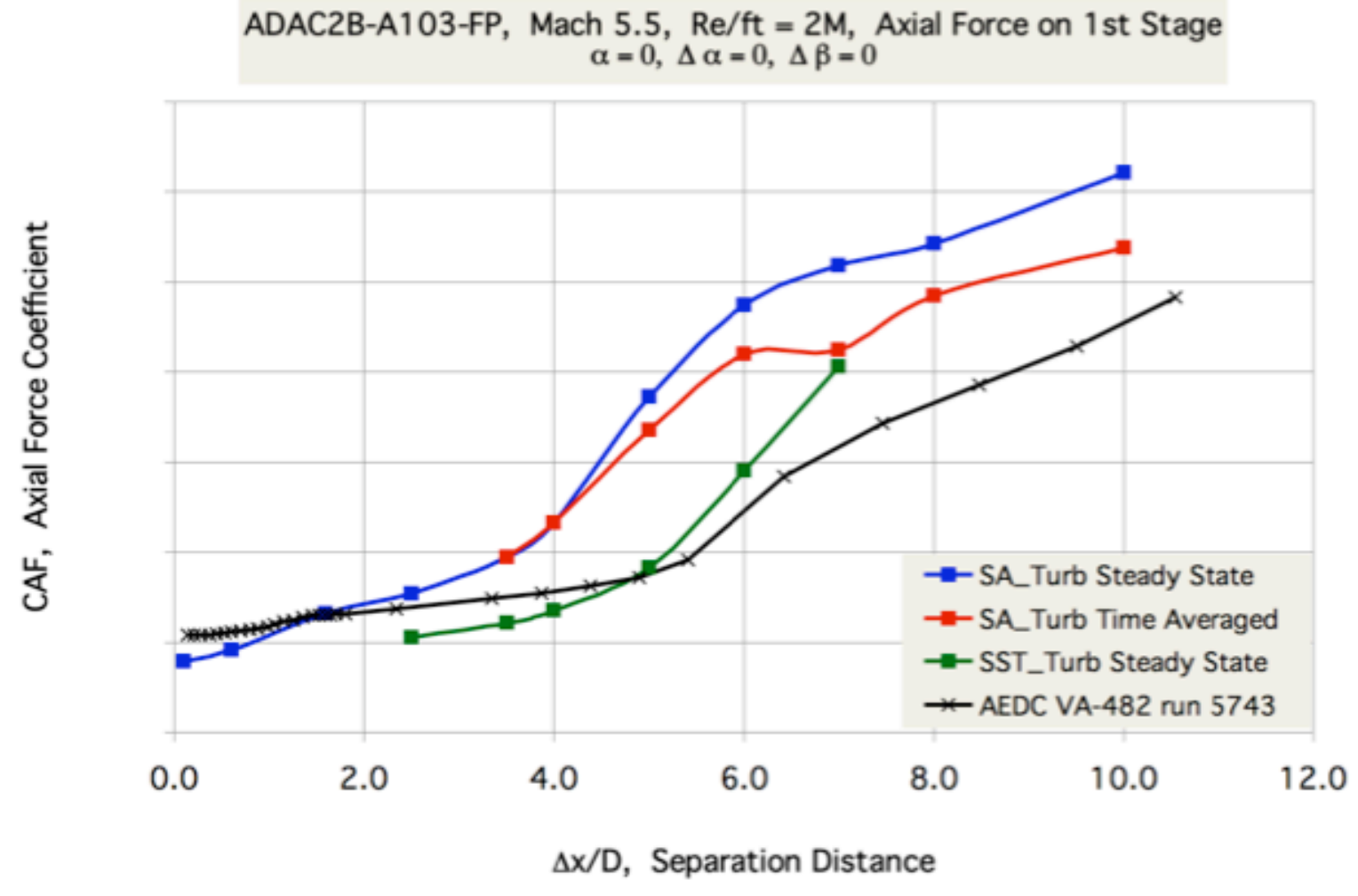

Figure 14. Ares I first stage separation test wind tunnel comparisons with CFD predictions at $\mathrm{M}=5.5$. 


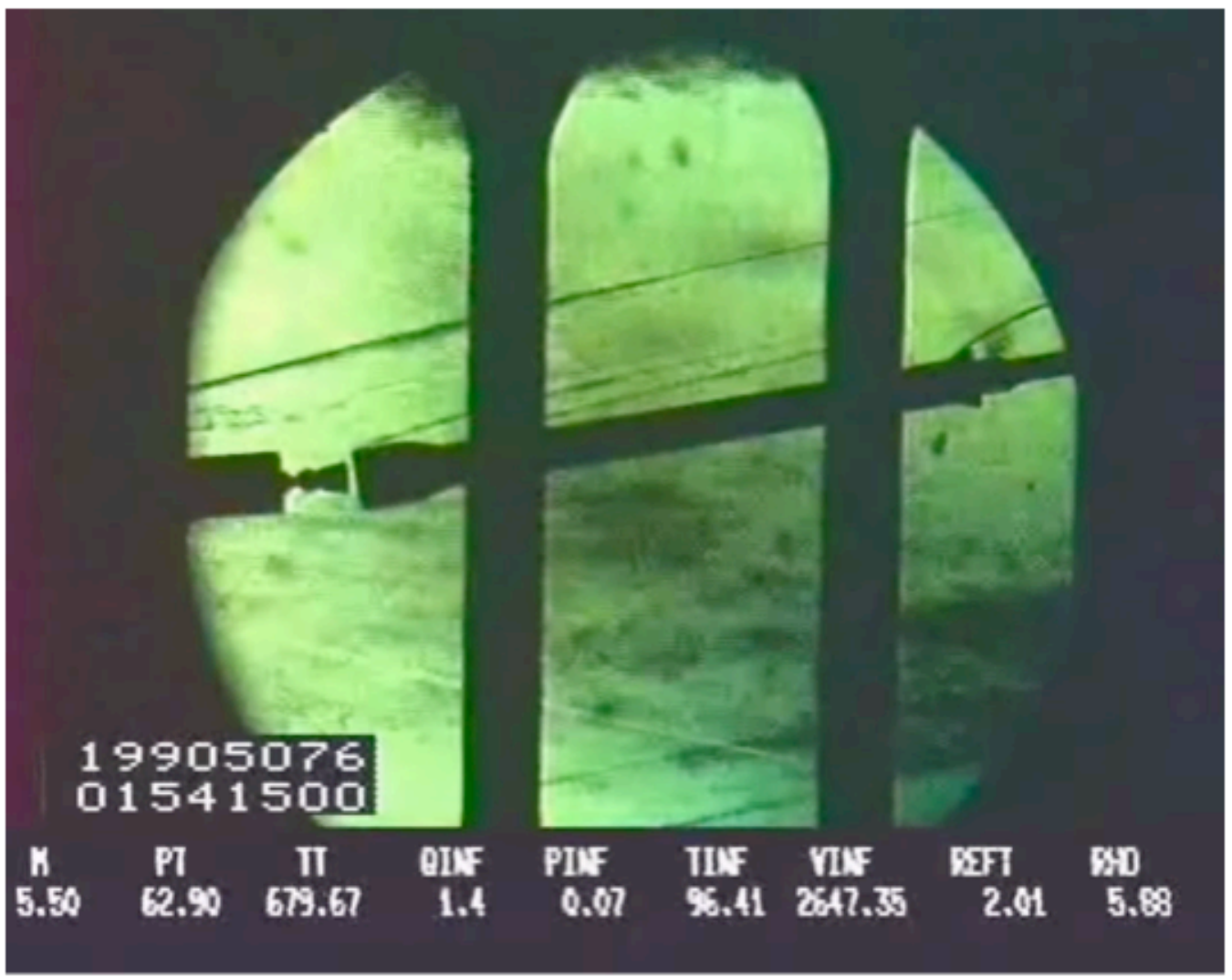

Figure 15. Ares I stage separation test Schlieren photograph at $\mathrm{M}=5.5$.

\section{Conclusion}

The Aerodynamics Team for the Ares program is developing very detailed, high fidelity experimental aerodynamics databases for all phases of the Ares I trajectory. These experimental investigations have included some complex test techniques, and the team has overcome some challenging technical issues during the testing program. Along with a complementary high fidelity CFD effort, these two disciplines have worked together to provide a high quality aerodynamic product to the Ares discipline customers in a timely manner and within schedule constraints. There are still some outstanding issues that need to be resolved before flight however. Included in this list would be powered testing, to validate some of the CFD methods that have been conducted for powered stage separation simulations and jet interaction effects, as well as high Reynolds number integrated aerodynamic force/moment effects that to date have not been validated by the experimental community. 


\section{References}

${ }^{1}$ Hall, R. M., Holland, S. D., and Blevins, J.A., "Aerodynamic Characterization of a Modern Launch Vehicle," AIAA Aerospace Sciences Meeting, NASA CP10817, 2011.

${ }^{2}$ Erickson, G. E., and Wilcox, F. J., “Ares I Aerodynamic Testing at the NASA Langley Unitary Plan Wind Tunnel,” AIAA Aerospace Sciences Meeting, NASA CP10544, 2011.

${ }^{3}$ Pinier, J. T., Niskey, C. J., Hanke, J. L., and Tomek, W. G., “Ares I Aerodynamic Testing at the Boeing Polysonic Wind Tunnel,” AIAA Aerospace Sciences Meeting, NASA CP10848, 2011.

${ }^{4}$ Capone, F. J., Paulson, J., and Erickson, G. E., "Lift-off and Transition Aerodynamics of the Ares I (A106) Launch Vehicle,", AIAA Aerospace Sciences Meeting, NASA CP10649, 2011.

${ }^{5}$ Pinier, J. T., and Niskey, C. J., “Ares I and Ares I-X Stage Separation Aerodynamic Testing,” AIAA Aerospace Sciences Meeting, NASA CP10840, 2011. 